\title{
France backs down on radical reform after resistance from researchers
}

Paris. France's conservative government has backed away from ambitious plans to transform the country's research system following its six-month national 'consultation' on research, which culminated this week with a colloquium in Paris attended by prime minister Edouard Balladur.

When the coalition government came to power last year, some of its more conservative members pushed for the dismantling of public research organizations and a reinforcement of the university system. They also urged the government to reorientate research heavily towards wealth creation.

During the consultation, however, many scientists told the government that this was unrealistic. Last week saw the release of a "manifesto for research", signed by over 1,200 leading researchers, warning that a radical reorganization of the research system would provoke harsh resistance.

Speaking at the national colloquium, François Fillon, the minister for higher education and research, said that the government would not dismantle the research organizations. "The ideological debate about killing the CNRS [Centre National de la Recherche Scientifique] is now dead", he told the meeting.

\section{Genome research consortium backed}

London. A group of top British geneticists has suggested the setting up of a consortium of the main academic groups in the field, and involving both research councils and pharmaceutical and biotechnology companies, to develop the commercial applications of genome research.

In a report commissioned by the Office of Science and Technology and published in London on Tuesday, the group also recommends the creation of a mouse genome centre, to include expertise in genetic and physical mapping, and in positional cloning.

It emphasizes that Britain's strong clinical base forms an ideal platform for the successful exploitation of genome research. But it warns that the opportunity could be jeopardized if this base is damaged by moves to place the National Health Service on a more commercial footing.

The report was commissioned last year as one of the first acts of a newly-created Advisory Committee on Human Genome Research, set up by the government to suggest ways of building on the strengths of genome research in the UK and securing its potential benefits for health-care and for British industry.

Drawn up by an expert working group
Fillon said that during the consultation he did not hear many voices raised against the research organization. Moreover, he needs the consultation to succeed following his aborted effort to reform the universities (see Nature 364, 472; 1993), and after successive climbdowns - on a restructuring of Air France and a low wage scheme for young people - the government cannot afford to lose a further confrontation.

Fillon says he heard much criticism of the rigidity of the French research system. But even here, he has conceded to the demands of researchers that reforms of such problems requires a continued growth in the research budget, even at a low rate.

Among the reforms that Fillon proposes are the creation of a single professional status for researchers that would allow them to move freely between the research organizations, the universities and industry.

He also wants a national committee to establish national priorities in research. But he accepts that the research community itself is best placed to determine these. While claiming that excessive government control would diminish the diversity of research and innovation, he says that managing research on the basis of market needs is based on an

chaired by Kay Davies, director of the Medical Research Council's (MRC's) new Clinical Sciences Centre at the Royal Hammersmith Postgraduate Hospital in London, the report focuses attention on two particular aspects of genome research: the need to improve the services provided by genome data bases, and ways of increasing the effectiveness with which research results are used by the private sector.

"Two things are wrong with current databases," says Davies. "First, many scientists do not have access to a decent database; and second, industry does not get access to the information as fast as it would like."

The new consortium is suggested by the working group as one way of encouraging the exploitation of genome research. It suggests that, like a small company, the consortium would have its own laboratories where much of the work would take place.

According to members of the working group, one potential co-ordinator for the new consortium would be the MRC's Human Genome Mapping Project Resource Centre. This is shortly to move to Hinxton Park in Cambridge, where it will be adjacent both to the Sanger Centre and the new European Bioinformatics Institute. obsolete linear model of innovation, and would be an "error".

Fillon admits that, despite the national consultation, he will have fewer firm recommendations than he expected to put to a debate on science planned for the National Assembly in June, an occasion which the

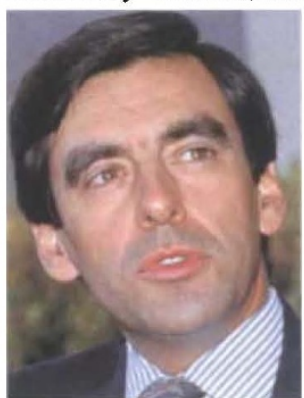

Fillon: keen to avoid conflict. government plans to use to launch a new national strategy for research.

Some observers claim that the national colloquium's failure to propose many policy changes is a sign of good sense. "Fillon has learnt that there is no sense in declaring war [on the research community]", says one government official. Indeed, the minister diplomatically welcomed last week's manifesto as a "constructive, if loud, contribution" to the consultation.

The manifesto was signed by 33 of the 40 members of the national committee of the CNRS, as well as all seven heads of its scientific departments and almost all its scientific board. It was also signed by six heads of scientific boards of the biomedical research organization INSERM, and $30 \mathrm{mem}$ bers of the national university committee.

Its basic message was that the government should think twice before radically reforming the research system. HenriEdouard Audier, a chemist at the Ecole Polytechnique who organized the manifesto, says that it was intended as a form of self defence.

The lack of conclusions from the consultation has also reassured many researchers, who considered that the process had been rushed. They were also concerned that neither CNRS nor INSERM were represented on the committee which drafted its agenda.

Another major concession from Fillon is a decision to seek an immediate solution to the problem of scientific recruitment. Over half of all French researchers will retire by 2005, and Audier has called on the government to begin recruiting now in order to preserve a sensible age pyramid.

For his part, Balladur confirmed that he considered research a national priority. But the many who expected him to focus on the value of research in boosting competitivity were surprised when he said that the main purpose of a strong science base was to provide France with political and cultural influence.

Declan Butler 